\title{
Multidisciplinary audit in primary healthcare teams: facilitation by audit support staff
}

\author{
H M Hearnshaw, R H Baker, N Robertson
}

\section{Introduction}

The policy of the NHS Management Executive is for audit to become clinical and multidisciplinary.' It predicts that "audit will become largely multiprofessional and part of a wider quality management programme that spans all aspects of care in hospitals and the community." In this context clinical audit can be seen as a necessary precursor to a quality system for the NHS.

Teamwork is a desirable ingredient for modern quality techniques such as total quality management, ${ }^{2}$ and the need for doctors to become skilled and effective team members has been acknowledged if quality management is to be implemented in the NHS. ${ }^{3}$ In 1991 a report from the National Association of Quality Assurance in Health Care pointed out that teamwork is the best way to provide comprehensive and high quality primary care and called for a single route for the management of teams and the development of local multidisciplinary groups, perhaps derived from medical audit advisory groups (MAAGs), to support multidisciplinary audit. ${ }^{+}$Since audit is concerned with improvement and therefore with change it is also concerned with new ideas and practices. FirthCozens pointed out that "because teamwork is the most effective means of bringing about innovation in organisations, we should look to teams in order to address the demands for change that the audit process entails ${ }^{5}$ ".

Most healthcare professionals work in groups, some in many different groups at different times and for different purposes. Pritchard and Pritchard defined a team as a group of people who make different contributions towards the achievement of a common goal." The members of a primary healthcare team have a common purpose in providing health care and thus can be described as a team, although it is recognised that the membership of the team in primary health care is open to debate. The accepted model for providing primary care is teamwork from a multidisciplinary team. ${ }^{78}$ Nevertheless, despite encouragement for developing teams there remain concerns that teams do not always function satisfactorily ${ }^{9}{ }^{10}$ and that the characteristics of the team, including tolerance of diversity and the levels of commitment and collaboration, influence the level of innovation. ${ }^{11}$
In their attempts to develop multidisciplinary audit, teams may obtain several different types of support. Support has been offered by family health services authorities. ' The Health Education Authority has organised a national facilitator development project which has been promoting team workshops for primary healthcare teams, run by local organising teams representing the local health authorities. ${ }^{13}$

Many MAAGs have recognised the need to encourage multidisciplinary audit in primary care and have provided training courses for team members other than doctors. In undertaking clinical audit, teams need to develop a range of methods and skills to help them (a) identify and agree problems for audit, (b) select criteria and standards, ${ }^{1 /}$ (c) allocate responsibility for the data collection and analysis, (d) identify deficiencies in performance, (e) select an effective implementation strategy, and $(f)$ organise continued monitoring. For each of these steps the team requires shared objectives, good communication, and mutual understanding.

The arrival of clinical audit has therefore given a new impetus to the examination of teamwork. If this renewed interest is to bring about improvements in care for patients guidance is needed on methods that can be used by teams. In order to encourage and foster audit many MAAGs now employ lay audit support staff who have a range of backgrounds and various job titles. ${ }^{15}$ These staff may be able to offer support to primary healthcare teams in the introduction of multidisciplinary audit, but methods are needed which are simple, effective, and acceptable both to the teams and to the audit support staff.

This article shows how audit support staff can help teams adopt multidisciplinary clinical audit by describing an observational study in which a model of clinical audit for primary care teams was developed and used by audit support staff with a group of primary healthcare teams.

\section{Model of team audit}

In order to translate the concept of multidisciplinary audit into observable and measurable activities, a model of multidisciplinary audit called the team quality system (TQS) was developed based on the widely 
used model of audit in general practice described by Baker and Presley. ${ }^{16}$ The model includes the audit cycle with the addition of a formal arrangement to ensure that the process of identifying problems, undertaking audit, and implementing change is managed by the team according to a formally agreed policy or plan. ${ }^{17}$ An instrument was developed from the model to measure to what extent the study teams changed their structured approach to multidisciplinary audit over the course of the study. The instrument was a six item questionnaire, each question having five possible responses and covering the dimensions of structure, attitude and strategy, applied both to teamwork and the team's approach to audit. These dimensions have been used to identify necessary components of a functioning team. ${ }^{18}$

The TQS questionnaire was developed solely as an indicator of change in the team's structure, attitude, and strategy concerning multidisciplinary audit. For example, the question covering strategy for audit was as follows.

"Which statement best describes your team management of audit:

(a) We have done no audit

(b) Some individuals have done some audits

(c) Some members of the team, working together, have done some audits on occasions

(d) The team as a whole has coordinated and conducted an audit

(e) Audit is a central part of our practice team management."

For each question the statements were in ascending order of systematic management of multidisciplinary audit by the team. The scores were thus measured on an ordinal but not an interval scale.

\section{Audit teams}

The study was undertaken in Leicestershire. All 147 practices in the county had been invited to help this audit centre to evaluate methods of audit and 50 had agreed. We sent an invitation to participate in the study to the general practitioner (GP) audit contact in each of these 50 practices; 23 GPs agreed to take part. In order to have a variety of practices included in the study the responding practices were divided into either more developed or less developed groups. The characteristics used to determine the categories were approval for vocational training (more developed), inner city (less developed), and three or more principals (more developed). ${ }^{19}$ From each of these two groups two practices were randomly selected to be participants and two others to be controls, giving a total of four participating and four control practices.

Of the four participant primary healthcare teams in the study, one was single handed, none was fund holding, and none was a training practice. Of the four control primary healthcare teams, one was single handed, one was fund holding, and one was a training practice. The information from the first administration of the TQS questionnaire showed that the teams were equivalent in their previous experience of audit. No practice in either group had, as a team, coordinated and conducted an audit, nor had any audit conducted by an individual included a repeated data collection, nor had any team conducted audit under a written policy.

The practice manager of each participant and control practice was visited by one of the research team and the study explained. The primary healthcare team was left to identify those members of staff who would take part, although a telephone discussion with the GP contact for audit in the practice had encouraged maximum attendance at the interventions and active participation by the partners. Limited financial reimbursement was offered to the teams to cover costs that might be incurred in inviting team members to meetings outside usual working hours.

All participant teams, comprising those members of staff appointed to take part, used the TQS questionnaire to assess their own quality system in the first and last intervention meetings. The completion of the questionnaire in the first intervention meeting stimulated discussion, and hence learning, about multidisciplinary audit by the members of the primary healthcare team involved.

The members of the four control teams, who included practice managers, GPs, practice nurses, health visitors, midwives, reception staff, and computer staff, who did not have any meetings with the audit support staff, completed the questionnaire, both at the beginning and end of the study period. The control team members self completed the questionnaires anonymously. The mode score of these teams for each question was used for comparison with the mode scores of the participant teams.

\section{Intervention meetings}

Each participant team experienced a series of five intervention meetings held on the practice premises and led by one of the two lay audit support staff employed by Leicestershire MAAG. The staff had no prior expertise in facilitation, nor in developing multidisciplinary work. For the study they were given two half day sessions in basic facilitation, and they had been involved in the planning of the intervention meetings. The TQS model was the basis for the following sequence of intervention meetings, which was designed by the research team and the MAAG audit support staff:

- Identify the team's situation in relation to audit and the particular barriers it faced in doing multidisciplinary audit

- Create a written team policy on audit to overcome those barriers

- Identify topics for audit, select one, and plan the audit

- Review results derived from the first data collection and agree necessary changes

- Review results derived from the second data collection and plan for the future management of team audit.

The meetings were timetabled over five months on dates agreed between the audit 
support staff and each participant team. Methods used during the intervention meetings included didactic presentation, whole group discussion, small group work, and individual work. Other techniques such as brainstorming and use of flip charts, handout materials, and homework were used to help team members develop an understanding of the subject matter as they worked through the audit cycle. The choice of methods was intended to maximise variety, appropriateness, and hence learning. ${ }^{20}$

The focus of the interventions was to help the primary healthcare team to agree a team policy for the management of clinical audit and guide team members through a complete audit cycle on a topic which they had chosen as a team. In achieving this, it was predicted that a beneficial side effect would be an improvement in team functioning and effectiveness.

Four measures were used to assess the effects of the programme of interventions. Firstly, the changes in scores between the first and second administrations of the TQS questionnaire were recorded and categorised by the direction of the change for each of the six questions: positive (towards more systematic multidisciplinary audit), no change, or negative (towards less systematic multidisciplinary audit). Secondly, the appropriateness of the materials and methods used in the interventions was assessed with ratings of the degree of engagement of team members. Engagement refers to the level of occupation of attention of a participant and was rated by observation of alertness, focus of attention, contribution to discussion, and lack of fidgeting on a scale from 1 (not engaged at all) to 5 (fully engaged). Each intervention meeting was systematically observed by a researcher and the meetings was recorded on video tape. Attendance at the meetings was also recorded as an indicator of sustained commitment to the programme of interventions. Thirdly, the audit support staff kept full records of the purpose, design, plan, results, and outcomes of the audits undertaken by the participant teams. Fourthly, the interventions were evaluated by the participant team members. Each team member completed an anonymous questionnaire designed to capture individual evaluations of the intervention meetings. The questions covered the methods and materials used by the audit support staff, overall views on the programme of interventions, and knowledge of audit. The questionnaires were given to all participating team members at the last intervention meeting, and they were asked to complete them after the meeting and return them in a stamped addressed envelope to the research team

\section{Outcome of intervention meetings}

All four participant teams drew up a team policy on audit which dealt with the barriers to audit which they had identified. However, one participant team withdrew from the study after the second intervention meeting because of staff illness and change in staff. The three remaining participant teams identified and discussed a list of possible topics for audit suggested by members of the team. Each team selected a topic from their lists using a simple scoring system found to be usable and acceptable for all team members.

The change in TQS questionnaire scores obtained by each participant and control team was calculated. In the participant primary healthcare teams the direction of change in TQS scores indicated development of the teams' approach to multidisciplinary audit. However, there was no trend for a change in mean scores in the control teams. The figure shows the mean change in the scores of the participant and control teams for each of the TQS questions.

The scores for engagement of team members for 142 activities during the intervention meetings were $57 \%$ at level 5 (fully engaged), $37 \%$ at level $4,8 \%$ at level 3 , and $0 \%$ below 3 . The attendance levels were consistently high at intervention meetings. Average attendance ranged from $79 \%$ to $91 \%$ of those appointed to attend the meetings, over the four teams. The table gives details of attendance.

Having agreed the selection of a topic for audit, each team was led through the design, running, and evaluation of the audit by the audit support staff facilitator. One primary healthcare team undertook an audit of waiting times in routine surgery coordinated by the practice manager. The standard was reached after the first data collection and confirmed by the second data collection undertaken over a longer period. The receptionists reported feeling more confident in reassuring patients that they would not have to wait long. Another primary healthcare team audited waiting times in open surgeries with a receptionist coordinating the audit. The standard was not met after the first data collection and it was agreed that doctors should aim for shorter consultations and start surgery more promptly. Although the standard was not reached by the second data collection, the waiting times had improved, and the team agreed that the initial standard it had set was unrealistically high. The third primary healthcare team audited incoming telephone calls and their appropriate referral to members of the team. The practice manager coordinated the audit. Most of the initial standards were reached after the first data collection, but changes were made to clarify referrals and include more information in the practice leaflet. The benefits were shown by the second data collection, which confirmed that the number of attempts a caller had to make to reach the required professional had fallen to an acceptable level.

Eighteen $(86 \%)$ completed evaluation questionnaires were returned. Most of the replies expressed positive views. Respondents stated that their understanding of audit had improved, that the methods and materials had been valuable, and that they had enjoyed taking part. 


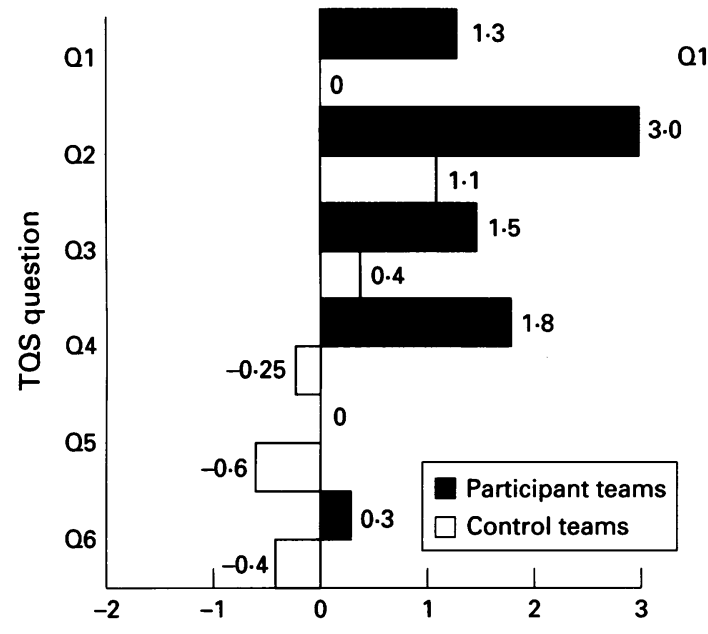

Q1 Team management of audit

Q2 Experience of audit

Q3 Feelings about audit

Q4 Team policy on audit

Q5 Thoughts about audit

Q6 Team functioning

Mean number of places changed on 5 point scale for team management of audit by three participant and four control teams

Attendance at intervention meetings of those appointed to attend

\begin{tabular}{|c|c|c|c|c|}
\hline & \multicolumn{4}{|c|}{ Practice } \\
\hline & $P 1$ & $P 2$ & $P 3$ & P4 \\
\hline $\begin{array}{l}\text { No of team members } \\
\text { GPs } \\
\text { Practice manager } \\
\text { Receptionists } \\
\text { Computer operator } \\
\text { Practice nurse } \\
\text { Health visitor } \\
\text { District nurse } \\
\text { Community midwife } \\
\text { Community psychiatric } \\
\text { nurse }\end{array}$ & $\begin{array}{ll} & 8 \\
3 & \\
1 & \\
1 & \\
1 & \\
1 & \\
1 & \end{array}$ & $\begin{array}{ll} & 7 \\
2 & \\
1 & \\
2 & \\
1 & \\
1 & \end{array}$ & $\begin{array}{ll} & 7 \\
1 & \\
1 & \\
2 & \\
1 & \\
1 & \\
1 & \end{array}$ & $\begin{array}{ll} & 6 \\
1 & \\
1 & \\
2 & \end{array}$ \\
\hline $\begin{array}{l}\text { No of meetings } \\
\text { Average attendance }\end{array}$ & $\begin{array}{l}5 \\
6.6\end{array}$ & $\begin{array}{l}5 \\
6.4\end{array}$ & $\begin{array}{l}5 \\
5.6\end{array}$ & $\begin{array}{l}2 \\
5.5\end{array}$ \\
\hline
\end{tabular}

\section{Discussion}

The aim of this paper was to show how audit support staff can help teams adopt multidisciplinary clinical audit. A model of team audit was developed and used to devise a series of meetings with the teams during the course of an observational study. All four measures of the effects of the interventions suggest that the facilitation provided by the audit support staff did help primary healthcare teams to introduce effective multidisciplinary audit. The findings disclosed a change in the participating teams towards a more developed, managed approach to multidisciplinary audit. They had moved from merely thinking about possible audit to having a policy on how audit should be managed, including how time would be allocated, delegation of the tasks of an audit, and reporting of findings to the team as a whole. They had successfully completed an audit managed by themselves and in addition had compiled a list of problems for future audits.

The TQS questionnaire was developed from the model of team audit, and its validity is supported by the results of the evaluation questionnaire which show how the teams developed their approaches to clinical audit. The evaluation questionnaire also showed that the meetings had been enjoyed by the participants. The findings supported those from the observation of the meetings, which indicated that the participants were engaged in the process. The positive emphasis gives support to the contention that the methods and materials used here could be used by other audit support staff and primary healthcare teams. A subsequent meeting at which the study results were presented to participants produced further positive comments on the interventions. The approach has subsequently been offered to, and accepted by, several other practices in Leicestershire.

For successful multidisciplinary audit, team members should understand and be part of the process of managing audit. The contents of the interventions in this study were based on the model of audit managed by the team and, in being successful in producing team audits, provide support to the validity of the model used. All these factors contributed to the success of the interventions.

The primary healthcare teams in this study were all volunteers. This self selection excluded both those primary healthcare teams who felt they were already undertaking multidisciplinary audit and those who were not interested or felt unable to undertake it. The method may not be suitable for all teams. A minimum level of teamwork is required to enable team members to discuss and agree participation in the programme of intervention meetings. For example, one participant team in this study felt it had to withdraw from the programme of meetings but hoped to resume when major changes within the team had been resolved. A certain stability of team membership is desirable in setting up team management of audit, but more important is a willingness by all team members to participate. Without this the task will be difficult for the audit support staff. Although a minimum level of teamwork is required, the meetings may themselves contribute to improved teamwork. Teamwork was not assessed during the study, but findings from the evaluation questionnaire completed by the team members do suggest that for some team members the level of participation in team activities had increased. Not all members of the primary healthcare team took part in the intervention meetings. The primary healthcare teams were left to appoint the participants themselves, although the partners were encouraged to take part to display support for the activity. The three participant teams completed audits which involved other members of the primary healthcare team and stated their intentions of taking the lessons learnt back to the full primary healthcare team for further implementation.

The programme of intervention meetings was completed with only three primary healthcare teams. It would be unwise to assume from the results, however positive, that the method would work for all. Experience of the methods in a larger number of practices is required. Nevertheless, the participants included a singlehanded primary healthcare team and non-fundholding, non-training primary healthcare teams, suggesting that the methods could be employed for a range of teams, not only those that are developed. The 
intervention meetings with each primary healthcare team were completed within a five month period and the length of time that the change in multidisciplinary audit will persist has not been established. This study did not include assessment of the life span of the changes begun during the study. We can only speculate on the duration of the effect of the interventions. A follow up meeting with representatives from the teams two months after the interventions ended showed that enthusiasm for audit has persisted beyond the end of the study, but long term change may require additional support. Other studies showed that benefits or changes wane over time. ${ }^{21}$ MAAGs and their audit support staff are in an ideal position to provide this long term support and encouragement to ensure that the transition to multidisciplinary audit continues.

The audit support staff had no previous training in facilitation, but they found that they could proceed with the interventions after brief familiarisation with the scheme, suggesting the methods could be used widely by other audit support staff without the need for additional training. The advantages of the use of an external facilitator in implementing clinical audit include the facilitator's special knowledge of audit and the skills to ensure improved communication and decision making within the team. The facilitator can ensure that the team continues to concentrate on the task and enable all members of the team to participate through techniques such as brainstorming and by encouraging the less vocal team members to contribute. Most MAAGs employ lay audit support staff who could, with a little training, facilitate the successful introduction of multidisciplinary audit to primary healthcare teams.

The authors thank the following for their help with this study: Roz Sorrie, Senior L iaison Officer, and Louise Darling, Liaison
Officer, Leicestershire MAAG; Alison Wilson, University of Leeds; Professor Robin Fraser, University of Leicester; and all the Leicestershire primary healthcare teams who took part. The study was funded by the Department of Health.

1 NHS Management Executive. Clinical ardit. London: Department of Health, 1993

2 Oakland JS. Total quality management. 2nd ed. Oxford: Butterworth-Heinemann, 1993

3 Berwick DM, Enthoven A, Bunker JP. Quality management in the NHS: the doctor's role. II. BMI 1992;304:304-8.

+ National Association for Quality in Health Care. Oualit through teamwork. Report of the Primary Care Spectalit. through teamwork. Report of the Prmam Care Specin

5 Firth-Cozens J. Building effective teams for audit. Quality. in Heulth Care 1992;1:252-5.

- Pritchard P, Pritchard J. Developing teamawerk in primary care. A practical ciorkhook. Oxford: Oxford Medical Publications, 1992

Roval College of General Practitioners. (Muality in sellurul practici. Iondon: RC.GP, 1985. Policy statement No 2.)

8 Secretaries of State for Social Services, Wales, Northern Ireland, and Scotland. Promoting better health. London: HMSO, 1987. (Cm 2.19.)

9) Gregson BA, Cartlidge A, Bond I. Interprofessional collaboration in primary health care organisations. collaboration in primary health care organisations. (Occasional paper 52.)

10 McClure I.M. Teamwork, myth or reality: community nurses' experience with general practice assessment. if Epidomiol Community Health 1984;38:68-74.

11 West MA, Wallace $\dot{M}$. Innovation in health care teams. Europian Fournal of Social Psychology 1991;21:303-15.

12 Allsop J. Changing primam care: the role of facilitutor. London: King's Fund Centre, 1990.

13 Lambert D, Spratley J, Killoran A. Primary halth car kum zorksshop mamual. London: Health Education Authority, 1991 .

14 Newton J, Hutchinson A, Steen N, Russell I, Haimes IE. Educational potential of medical audit: observations from a study of small groups setting standards. Quality in a study of small groups
Hicalth (iar 1992;1:256 9 .

15 Griew K, Mortlock M. A study of MAAG organisation and function. Audit Trends 1993;3:89-93.

16 Baker R, Presley P. The practici audit plan. London: Serem Faculty of the Royal College of General Practitioners, 1990.

17 Hearnshaw HM. The audit cycle managed by the primary care team. Audit Trends 1993;1:7-8.

18 Salas E, Dickinson T, Converse S, Tannenbaum S. Toward an understanding of team performance and training. In: Swezey R, Salas E, eds. Teams: thei training and pirSwezey R, Salas E, eds. Teams: their training and
formance. New Jersey: Ablex Publishers, 1992:3-26.

19 Baker R. Explaining variations in standards. Br f Gonl Prat $1992 ; 42: 415-8$.

20 Beard R, Hartley J. Teaching and learning in higher iducatum. London: Paul Chapman Publishing, 1984.

21 Harris CM, Fry J, Jarman B, Woodman E. Prescribing: a case for prolonged treatment. $7 \mathrm{R}$ cioll $G(n)$ Prat 1985;35:284 7 . 